Progress in Physical Geography 30, 3 (2006) pp. 409-431

\title{
Plant invasions: merging the concepts of species invasiveness and community invasibility
}

\section{David M. Richardson ${ }^{*}$ and Petr Pyšek ${ }^{2}$}

'Centre for Invasion Biology, Department of Botany and Zoology, Stellenbosch University, Private Bag X1, Matieland 7602, South Africa 2Institute of Botany, Academy of Sciences of the Czech Republic, CZ-252 43 Prühonice, Czech Republic, and Department of Ecology, Charles University Prague, CZ-128 01 Praha 2, Czech Republic

\begin{abstract}
This paper considers key issues in plant invasion ecology, where findings published since 1990 have significantly improved our understanding of many aspects of invasions. The review focuses on vascular plants invading natural and semi-natural ecosystems, and on fundamental ecological issues relating to species invasiveness and community invasibility. Three big questions addressed by the SCOPE programme in the 1980s (which species invade; which habitats are invaded; and how can we manage invasions?) still underpin most work in invasion ecology. Some organizing and unifying themes in the field are organism-focused and relate to species invasiveness (the tens rule; the concept of residence time; taxonomic patterns and Darwin's naturalization hypothesis; issues of phenotypic plasticity and rapid evolutionary change, including evolution of increased competitive ability hypothesis; the role of long-distance dispersal). Others are ecosystem-centred and deal with determinants of the invasibility of communities, habitats and regions (levels of invasion, invasibility and propagule pressure; the biotic resistance hypothesis and the links between diversity and invasibility; synergisms, mutualisms, and invasional meltdown). Some theories have taken an overarching approach to plant invasions by integrating the concepts of species invasiveness and community invasibility (a theory of seed plant invasiveness; fluctuating resources theory of invasibility). Concepts, hypotheses and theories reviewed here can be linked to the naturalization-invasion continuum concept, which relates invasion processes with a sequence of environmental and biotic barriers that an introduced species must negotiate to become casual, naturalized and invasive. New research tools and improved research links between invasion ecology and succession ecology, community ecology, conservation biology and weed science, respectively, have strengthened the conceptual pillars of invasion ecology.
\end{abstract}

Key words: biological invasions, biotic resistance, invasibility, invasiveness, long-distance dispersal, naturalization, phenotypic plasticity, plant invasions, propagule pressure, rapid evolution, residence time, taxonomic patterns, tens rule.

*Author for correspondence. Email: rich@sun.ac.za 


\section{Introduction}

Invasion ecology is the study of the humanmediated introductions of organisms, especially to areas well outside their potential range as defined by their natural dispersal mechanisms and biogeographic barriers. The field covers all aspects relating to the introduction of organisms, their capacity to naturalize and invade in the target region, their interactions with resident biota and, increasingly, the consideration of costs and benefits of their presence and abundance with reference to human value systems. Biological invasions have been chronicled for centuries, but Charles Elton's (1958) book The ecology of animal and plant invasions was the starting point of what has come to be known as invasion ecology (Rejmánek et al., 2005a).

This paper considers some of the most significant developments in the field of plant invasion ecology, with emphasis on work published since 1990 - after the publication of the global synthesis volume from the SCOPE programme on biological invasions (Drake et al., 1989). We have selected for discussion issues where there has been intense research interest and where new findings have significantly improved our understanding of invasions. Our focus is on vascular plants invading natural and semi-natural ecosystems, and on fundamental ecological issues relating to invasiveness and invasibility, rather than those relating to impacts and specific management concerns.

\section{Background}

Interest in biological invasions has exploded in the past two decades. The SCOPE programme of the 1980s (Drake et al., 1989) set the scene by revisiting some key assumptions and generalizations put forward by Elton (1958), reviewing the current status of invasions in many parts of the world, and calling on some of the world's top ecologists to apply their minds to the problems and challenges regarding biological invasions. The SCOPE programme addressed three fundamental questions: which species invade; which habitats are invaded; and how can we manage invasions? (Drake et al., 1989). Phase 1 of the Global Invasive Species Programme (GISP; Mooney, 1999) primarily sought practical solutions to the rapidly escalating problems, while realizing the need for improved understanding of some fundamental ecological aspects. The three big questions from the SCOPE programme still underpin most work in invasion ecology. The past decade has, however, seen considerable activity on numerous fronts, as the extent and impacts of invasive species have increased. Attempts have been made to strengthen the conceptual pillars of invasion ecology; these include moves to bridge the gap between the study of invasions and succession ecology, community ecology, conservation biology, and weed science. Many thorough studies have profiled key invaders and invaded systems (Weber, 2003), facilitating better generalizations. New approaches and technologies have been applied in addressing crucial issues; for example, molecular techniques, remote sensing, and advanced spatial analysis tools are shedding light on issues and processes that were out of reach of earlier researchers. Since humans cause and interpret invasions, there have been increased inputs from social scientists and economists, and social concerns are increasingly shaping research agendas. The increasing urgency in the search for unifying concepts has led to the generation of new hypotheses and generalizations. Our aim here is to review such organizing and unifying themes in the field, to evaluate these, and to suggest some challenges for the future.

Given the many interlinked elements of invasion ecology, there is no single ideal structure for a broad review such as the one we attempt here. Each part of the story demands a link to several others. The headings below start with an emphasis on general and overarching aspects, and move through organism-focused to ecosystem-centred considerations. The terminology used in the paper (following Richardson et al., 2000b; Pyšek et al. , 2004b) is outlined in Figure 1. 
A

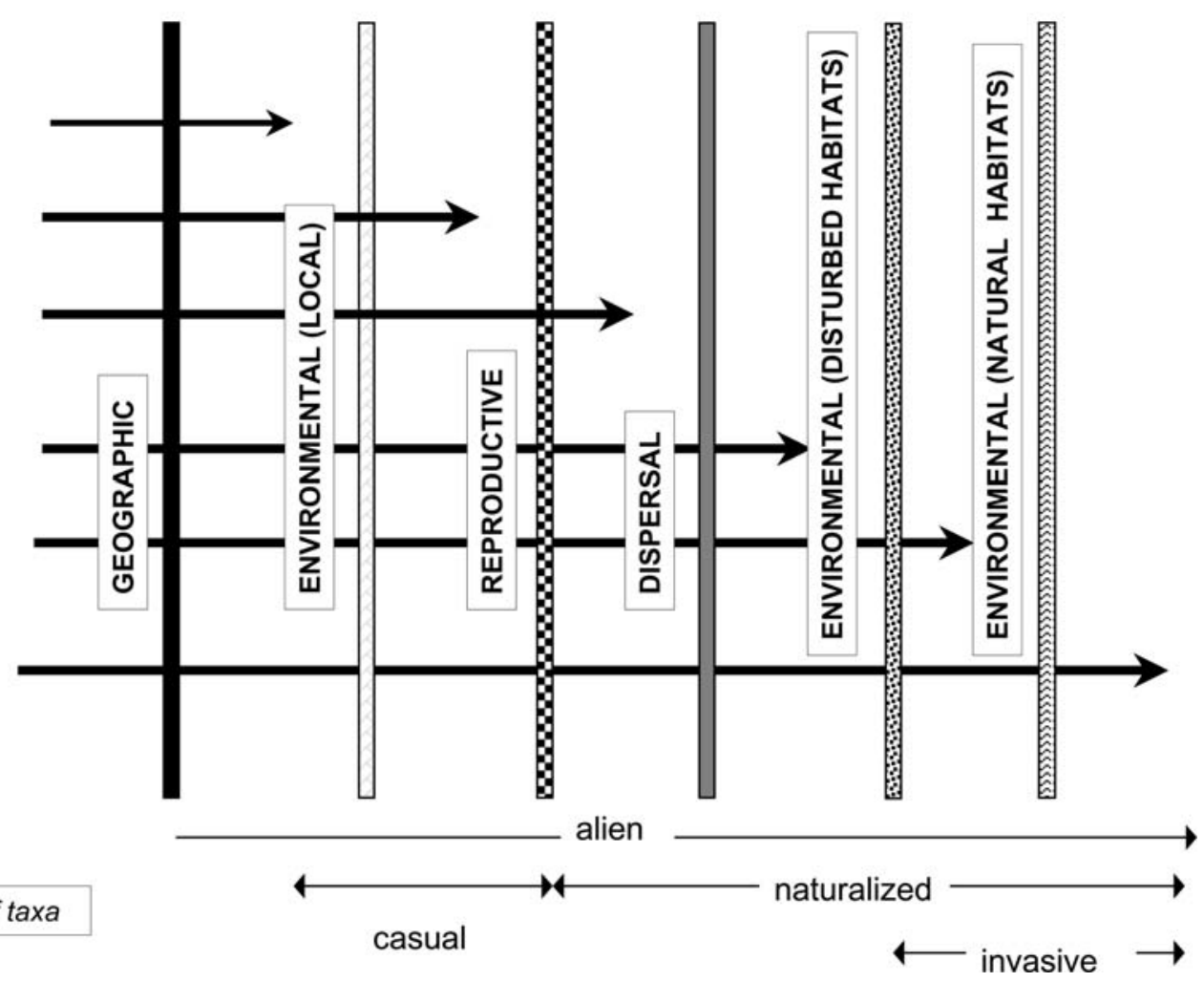

Figure 1 The 'naturalization-invasion continuum' (panel A) conceptualizes the various barriers that a plant must overcome to become alien, casual, naturalized or invasive in a new environment (adapted from Richardson et al., 2000b). The scheme also provides a framework for the objective definition of categories of alien plants (Pysek et al., 2004b). Alien plants are those whose presence in an area is the result of human-mediated transport. Casual alien plants are alien plants that may flourish and even reproduce occasionally outside cultivation but that eventually die out because they do not form self-replacing populations; they rely on repeated introductions for their persistence. Naturalized plants are those aliens that form self-replacing populations for at least 10 years without direct intervention by people (or despite human intervention) by recruitment from seeds or ramets capable of independent growth. Invasive plants are a subset of naturalized plants that produce reproductive offspring, often in large numbers, at considerable distances from parent plants, and thus have the potential to spread over a large area. Understanding of the dynamics of plant invasions requires insights on traits of the plant (elements of species invasiveness) and features of the environment (components of community invasibility), but neither aspect can be fully evaluated without reference to the other (panel B). Invasions are context specific, and invasiveness only materializes when certain environmental requirements are met. Boxes in panel $\mathbf{B}$ list the key concepts addressed in this paper 


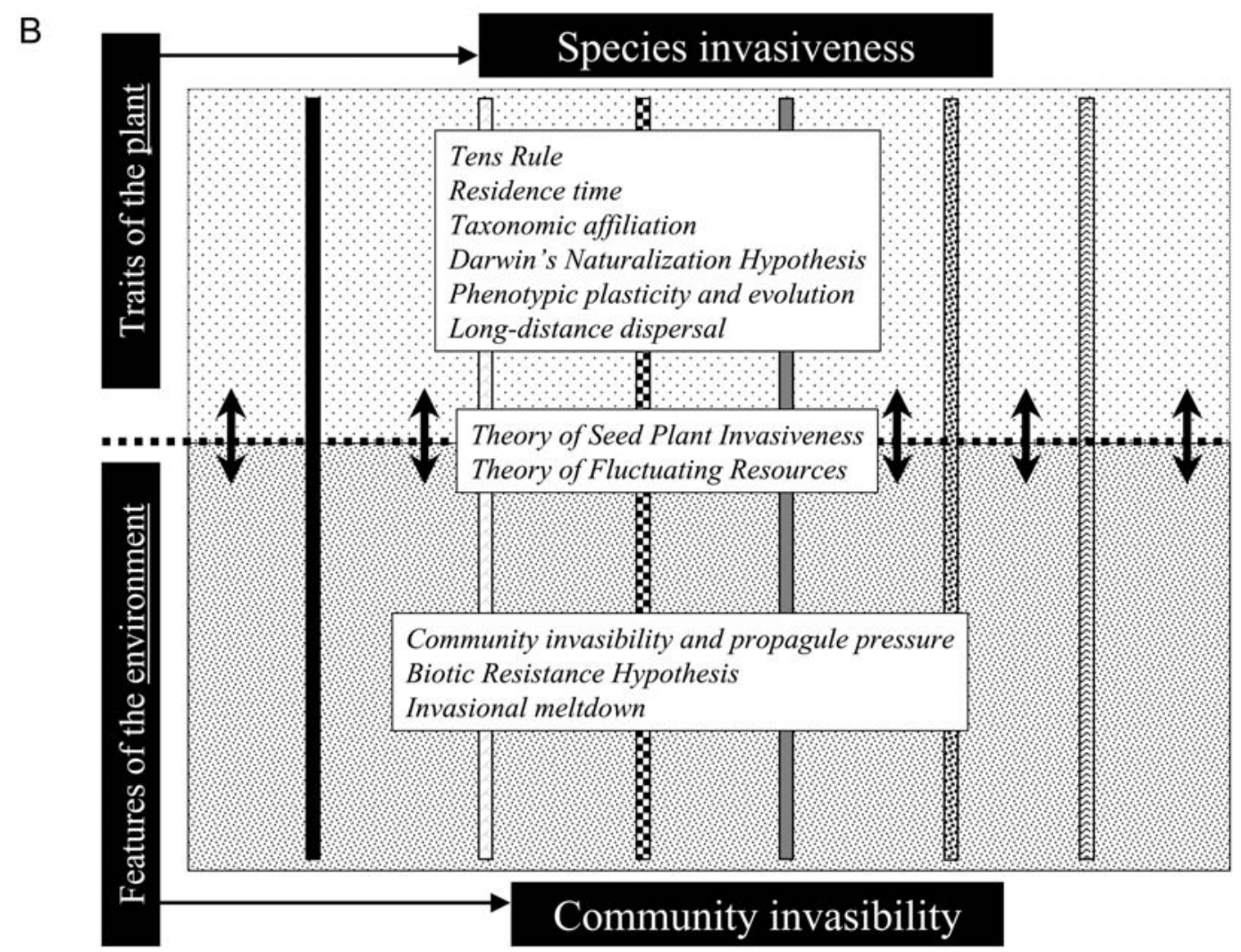

Figure 1 Continued

\section{How many invaders? The tens rule}

The tens rule (originally the ten-ten rule; Williamson and Brown, 1986) was proposed as a quantitative estimate of the proportion of introduced species that become pests (Williamson, 1993; Williamson and Fitter, 1996). It is a probabilistic assessment of the proportion of species that reach particular stages in the invasion process. It predicts that $10 \%$ of imported species escape to become casual, $10 \%$ of casuals become naturalized (sensu Richardson et al., 2000b), and 10\% of naturalized species become pests (sensu Pyšek et al., 2004b). The rule was derived from European plant data but the general principle that successful invasions are rare (the rule predicts that alien pests comprise very roughly only $1 \%$ of the introduced species found casual) holds for other regions and across many taxa of plants and animals (Williamson, 1996). The tens rule received considerable reaction, but has also been widely misinterpreted, mostly when applied directly to numbers of 'invasive' species. The reasonably constant proportion of alien taxa that invade across a wide range of systems is, at least partly, a result of the similar residence times (see section IV) of species in different alien floras (Rejmánek et al., 2005b). In other words, the tens rule is largely an artifact of the particular stage of invasions worldwide and this will change over time (Figure 2).

Despite the wide limits, the many exceptions (Williamson, 2000), and the caveats mentioned above, the tens rule is a useful generalization that can be used as a 


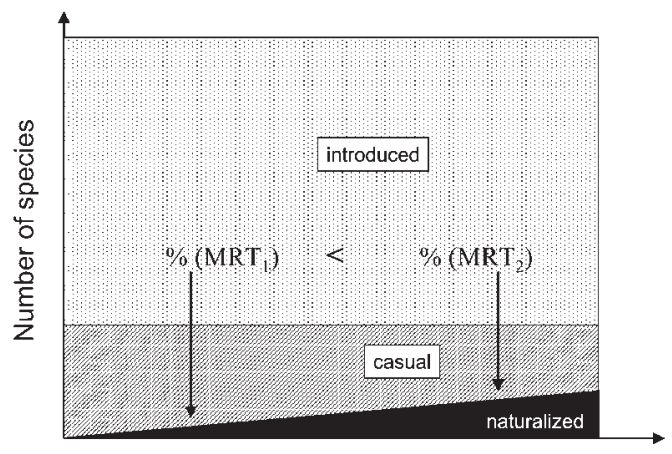

Residence time

Figure 2 The effect of residence time (MRT; see text) on the second transition of the tens rule (from casual to naturalized stage; see Figure 1). Even if the number of introduced and casual species remains stable over time, the proportion of casual species that become naturalized increases because increasingly more species have enough time to adapt or encounter suitable symbionts, climatic events or chance factors that potentially trigger invasion. The reasonably constant proportion of alien taxa across a wide range of systems is partly a result of the similar residence times of species in different alien floras. The proportion of naturalized species therefore depends on the date of assessment; it will be higher at $\mathrm{MRT}_{2}$ than at $\mathrm{MRT}_{1}$

benchmark to which real data can be related; deviations indicate taxa with higher or lower invasiveness and regions/habitats with lower or higher invasibility (Williamson, 1996; Gaston et al., 2003).

The tens rule also provides some basis for estimating the global number of naturalized species. Had all 260,000 of the world's vascular plant species been transported to regions remote from their native ranges (which is clearly an overestimated assumption as many rare species never get introduced), then the tens rule predicts 2600 naturalized species worldwide. Taking into account that the rule is supposed to hold within a statistically derived range of c. 5-20\%, allowing for biological variation and different approaches to the classification of species among researchers (Williamson, 1996), this gives for the two transitions an estimate of $13,000-52,000$ casuals and 650-10,400 naturalized species globally. This seems a more reasonable estimate (for now at least) than Rapoport's (1991) suggestion that at least 10\% of the world's vascular plant species are potential invaders. The figure derived from the tens rule has some support from real data, eg, from numbers of naturalized plant species estimated for Europe (1568; Weber, 1997) or New Zealand (2319; Randall, 2002).

Despite efforts to create lists of invasive alien species for different regions and for the whole world (Weber, 2003; see http://invasivespecies.nbii.gov/as/DraftIASDBs.htm), we clearly have insufficient information on which species can objectively be classified as 'naturalized' or 'invasive' (sensu Richardson et al., 2000b; Pyšek et al., 2004b). This is hindering our ability to develop sound generalizations on the correlates and determinants of invasiveness and invasibility. Accurately compiled lists and alien floras (using objective criteria) are essential for future progress in this respect (Binggeli, 1996; Richardson et al., 2000b; Pyšek et al., 2002b; 2004b).

\section{Time changes everything - the role of residence time}

Stochastic factors, including initial inoculum size, residence time, propagule pressure, and chance events, are crucial for determining of whether (or when) a species will invade (Rejmánek et al., 2005a). One of the most robust emerging generalizations in invasion biology is that the probability of invasion increases with the time since the introduction (residence time). As it is mostly not known exactly when a taxon was introduced, the term 'minimum residence time' (MRT) has been proposed (Rejmánek, 2000). A positive relationship between MRT and current 
distribution of alien species is evident for several regional floras (Crawley et al., 1996; Wu et al., 2003; 2004; Rejmánek et al., 2005a; see Pyšek and Jarošik, 2005, for a review), and for individual species at different scales (Richardson and Higgins, 1998; Müllerová et al., 2005). MRT explains not only the range and frequency of current distributions but also the invasion status of a species. In the Czech Republic casual species have significantly shorter mean MRT than naturalized and invasive aliens (Pyšek and Jarošík, 2005). Residence time integrates aspects of propagule pressure: the longer the species is present in the region, the greater the size of the propagule bank, and the greater the probability of dispersal, establishment, and the founding of new populations (Rejmánek et al., 2005a). The effect on the invaded community also increases with residence times (Collier et al., 2002). In Europe, the effect of residence time is still obvious after several millennia of plant invasions. Those archaeophytes (sensu Preston et al., 2004; Pyšek et al., 2004c) that invaded soon after the beginning of Neolithic agriculture are more common and have wider distribution ranges than those that arrived later (Pyšek and Jarošík, 2005). Residence time also affects the ecology of weed communities on arable land where both groups of aliens distinguished in Europe according to the time of introduction meet; archaeophytes are more common in old crops such as cereals than in more recently introduced crops, where neophytes are most numerous (Pyšek et al., 2005).

MRT is a crucial consideration in studies evaluating determinants of invasiveness; an analysis of naturalized neophytes of the Czech flora showed that MRT was more important than selected species traits for explaining their current distribution (Pyšek and Jarošik, 2005). This suggests that unbiased evaluation of factors affecting invasiveness of alien species can be only obtained if the confounding effect of MRT is factored out. Since many species have not been present for long enough to naturalize and become invasive, the importance of any particular plant trait in determining the success or failure of invasion is discernible only after the species has either established or failed in a new region (Williams et al. , 2002). Residence time must also be considered when labelling species as invasive or non-invasive in different parts of the world - an important step in most screening protocols where the performance of a species elsewhere (invasive or not) is often used (often uncritically) as a crucial input. MRT is closely associated with the lag phase (also termed 'latency period') that often precedes invasions of alien species the delay between the start of invasion and the typical phase of exponential increase (Baker, 1965; Kowarik, 1995). The phenomenon of lag phases has important implications for the tens rule (see section III), because the considerable lags preceding invasions mean that the patterns we observe today are largely the net result of introductions and prevailing conditions and processes from over a century ago (Hulme, 2003). A practical implication of this is that, because of the lag phase, biological invasions have a built-in inertia - the number of naturalized and invasive species will increase in the future even if no additional introductions are made (Kowarik, 1995; Figure 2). Preventive measures need to address not only precluding further introductions of high-risk species, but also screening and monitoring of already introduced species, some of which are 'sleeper weeds' (sensu Groves et al. , 2003).

\section{Born under a bad sign - taxonomic patterns in alien plant invasions}

Not all species/genera/families have been moved around to the same extent, so opportunities to become naturalized and invasive are not even among taxa. Even with the caveat that the large-scale natural experiment of human-mediated rearrangement of regional floras is imperfect, it is clear that invasive alien plants are non-randomly distributed within higher taxonomic groups, 
whether considered globally (Daehler, 1998; Pyšek, 1998), continentally (Weber, 1997), or regionally (Williams et al., 2002; Wu et al., 2004; Pauchard and Alaback, 2004; Villasenor and Espinoza-Garcia, 2004). This pattern has a phylogenetic background. When related to the global species pool, families with a disproportionally high representation of invasive aliens are concentrated within the classes Asteridae, Caryophyllidae and Commelinidae (Pyšek, 1998). At the family level, Amaranthaceae, Brassicaceae, Convolvulaceae, Malvaceae, Poaceae, Papaveraceae, and Polygonaceae are consistently over-represented in invasive-alien floras, and Fabaceae are highly successful as invaders of natural areas (Weber, 1997; Daehler, 1998; Pyšek, 1998; Wu et al., 2004). Many families of aquatic or subaquatic (Alismataceae, Hydrocharitaceae, Nymphaeaceae,

Potamogetonaceae, Typhaceae; Daehler, 1998) and woody plants (Myrtaceae, Rosaceae, Salicaceae, and Tamaricaceae; Williams et al. , 2002) are overrepresented among high-impact invaders. There are very few invasive aliens in the Orchidaceae and Rubiaceae (Daehler, 1998; Pyšek, 1998). The non-random distribution is also reflected in differences in naturalization rates of particular families. In New Zealand, Juncaceae, Poaceae and Salicaceae are several times more likely to naturalize than the average (Williams et al., 2002).

Evidence for invasiveness being phylogenetically related also at lower taxonomic levels comes from a study of gymnosperms. Twenty-eight of the 36 gymnosperms known to be invasive worldwide (78\%) belong to one family (Pinaceae) and 21 of these belong to the genus Pinus (Richardson and Rejmánek, 2004). Using an index of invasiveness, defined as the number of invasive species/number of rare or threatened species within a family, Richardson and Rejmánek (2004) concluded that, despite being often portrayed as less successful in an evolutionary sense, some groups of conifers have similar or higher levels of invasiveness as highly invasive angiosperm families comprising predominantly woody taxa, eg, Sapindaceae, Betulaceae, Eleagnaceae and Salicaceae.

\section{Family ties - Darwin's naturalization hypothesis}

De Candolle (1855) noted that naturalized species are more likely to recruit from genera with no native species in a given region. Darwin (1859) used this observation to support his theory of intense competition between congeners leading to easier naturalization of species from non-allied genera. Darwin's naturalization hypothesis (DNH) has attracted renewed interest recently as lists of naturalized plants become available for more regions of the world (Daehler, 2001). Two studies (Mack, 1996; Rejmánek, 1996) provided support for the hypothesis. Rejmánek (1996) determined that in three families (Asteraceae, Fabaceae, and Poaceae) European species naturalized in California are statistically more likely to belong to alien (non-American) genera than expected from a random pool of European species. The same pattern was found in the Australian flora (Rejmánek, 1999). Daehler (2001) pointed out that if the phenomenon proved to be universal, it could potentially lead to statistically based rules that could help to understand the assembly of invaded communities. To test the validity of the hypothesis he undertook the most rigorous study to date, examining 20 plant families in Hawaii. Interestingly, he also considered residence time (see section III), to see whether alien species once naturalized, hence present in the flora, become honorary natives and influence the naturalization success of late arrivals. He found no support for $\mathrm{DNH}$. Indeed, for some families the pattern was opposite to that predicted by $\mathrm{DNH}$. The same result emerged for the naturalized flora of New Zealand (Duncan and Williams, 2002). This suggests that for an introduced plant, the advantages of having close relatives, on average, outweigh the drawbacks (Williams, 1951) and that alien species from native genera have better chances of 
naturalizing because they share with their congeners some level of preadaptation to the conditions of the invaded region - a notion originally articulated by Darwin (1859). Daehler (2001) suggested that the contrasting results in previous studies may be due to differences between families and regions, or because island and mainland communities are possibly regulated by different factors. $\mathrm{DNH}$ clearly does not hold in all situations, but the concept has stimulated some informative research and drawn attention to key aspects of naturalization in invasive plants.

\section{Getting ready for the conquest - phenotypic plasticity and/or rapid evolution?}

For an introduced plant species to invade a new region (ie, establish and proliferate across a range of environmental conditions) two basic options are available: either the plant must possess sufficiently high levels of physiological tolerance and plasticity, or it must undergo genetic differentiation to achieve required levels of fitness. The options are not mutually exclusive. A 'general-purpose genotype' (sensu Baker, 1965) facilitates spread of populations founded by small numbers of individuals through reproductive systems such as autogamy (selfing) that do not promote genetic exchange but do provide reproductive assurance. If an introduced species does not have a general-purpose genotype, it will be confined to a restricted area until genetic alteration, through recombination, introgression or mutation, allows it to grow and flourish across a wider range of sites. Much research in the past decade has explored the relative importance of plasticity versus rapid evolution across a wide range of systems and many taxa (Reznick and Ghalambor, 2001; Bossdorfet al., 2005). Phenotypic plasticity is undoubtedly important for many invasive species from many taxonomic groups and in diverse habitats. A few examples where this has been demonstrated are: Alliaria petiolata in New Jersey (Byers and Quinn, 1998), Bunias orientalis in Germany (Dietz et al.,
1999), Carpobrotus spp. in coastal California (Weber and D'Antonio, 1999), Clidemia hirta in Hawaii (DeWalt and Hamrick, 2004), Pennisetum setaceum in Hawaii (Williams et al., 1995), and Verbascum thapsus in California (Parker et al., 2003). Daehler (2003) reviewed case studies available and showed that invasive species have greater phenotypic plasticity than co-occurring native species.

Evolution can serve as another potential explanation for invasion success. Evolution can be rapid and is relevant to ecological studies (Thompson, 1998). Invasive plants may evolve by genetic drift and inbreeding in founder populations, by intra- and interspecific hybridization in the introduced range creating novel genotypes, and by drastic changes in selection regimes imposed by novel environments that may cause adaptive evolutionary change (Bossdorf et al., 2005). Hybridization can lead to adaptive evolution in a number of ways, including fixed heterozygosity via polyploidy (Ellstrand and Schierenbeck, 2000; Clements et al., 2004). Polyploids have many characteristics that allow them to maintain higher levels of genetic diversity, compared to diploids, and therefore to cope with problems of a small founder population (Soltis and Soltis, 1993; Levin, 2002). Hybridization has been shown an important mechanism of evolution of invasive species (Ellstrand and Schierenbeck, 2000; Vila et al., 2000; Daehler and Carino, 2001) and many widespread and successful invaders are recently formed allopolyploid hybrids (Abbott, 1992; Lee, 2002). Building on the work of Baker (1965) and Stebbins (1985), much recent research has explored the role of the evolution of polyploidy in facilitating invasions - eg, for Brassicaceae (Hurka et al., 2003), Impatiens glandulifera (Kollmann and Banuelos, 2004), Rubus alceifolius (Amsellem et al., 2001), and Senecio cambrensis (Abbott and Lowe, 2004). Increased performance of hybrid taxa or genotypes has been documented for a number of species (Vila et al., 2000; Pyšek et al., 2003b; Mandák et al., 2004). 
Many studies have found at least partial support for the 'evolution of increased competitive ability' (EICA) hypothesis which predicts that plants introduced into an environment that lacks their usual herbivores will experience selection favouring individuals that allocate less energy to defence and more to growth and reproduction (eg, Blossey and Nötzold, 1995; Leger and Rice, 2003; Siemann and Rogers, 2003; Jakobs et al., 2004; Maron et al., 2004; Rogers and Siemann, 2004). Other studies found no support for EICA (eg, Willis et al., 2000; Thébaud and Simberloff, 2001; Bossdorf et al., 2004) or the opposite of what EICA predicts (Wolfe et al. , 2004). However, only a few studies provided a full test of the EICA hypothesis by addressing both growth and defence in the same species (Bossdorf et al., 2005). Elegant evidence for the EICA hypothesis was recently provided by Zangerl and Berenbaum (2005). By examining herbarium specimens of alien Pastinaca sativa in North America over 152 years, they revealed phytochemical shifts towards increased toxicity coincident with the accidental introduction of a major herbivore from its native range. Overall, there is reasonable empirical evidence that genetic differentiation through rapid evolutionary change plays an important role in plant invasions (Bossdorf et al., 2005). Nevertheless, available evidence suggests that some invaders are 'born' (released from fitness constraints), and some are 'made' (they evolve invasiveness after colonization) (sensu Ellstrand and Schierenbeck, 2000), and that the relative importance of ecological and evolutionary forces seems to be unique to each plant invasion episode.

\section{Go far away and multiply - long-distance dispersal}

Observed rates of spread vary greatly among invasive plants in different habitats and regions and many invasions show extremely fast spread rates. The comparative analysis of the spatiotemporal dynamics of over 100 taxa from studies undertaken worldwide (Pyšek and
Hulme, 2005) indicates that average rates of local spread of invasive species range from $2 \mathrm{~m} \mathrm{yr}^{-1}$ to $370 \mathrm{~m} \mathrm{yr}^{-1}$ but average rates of long-distance dispersal are at least two orders of magnitude greater than estimates of local dispersal, with the highest value of $167 \mathrm{~km} \mathrm{yr}^{-1}$ recorded for Wedelia trilobata over a 15-year period (Batianoff and Franks, 1997). However, the maximum values recorded are many times higher than the mean. For example, over a period of 50 years, one population of Opuntia stricta spread up to $18.5 \mathrm{~km}$ from its origin, an average rate of $370 \mathrm{~m} \mathrm{yr}^{-1}$ (Foxcroft et al., 2004). But even in the first two years outlying populations were established up to $14 \mathrm{~km}$ away. Estimates of the area occupied through local spread have sometimes been drawn from aerial photographs and maximum recorded values range between 1100 and $2000 \mathrm{~m}^{2} \mathrm{yr}^{-1}$ (for Rhododendron ponticum, Heracleum mantegazzianum and the alga Caulerpa taxifolia; Pyšek and Hulme, 2005). For longdistance spread, most studies indicate 3 to $500 \mathrm{~km}^{2} \mathrm{yr}^{-1}$, but indirect estimates drawn from distribution maps can give much higher values up to $5000 \mathrm{~km}^{2} \mathrm{yr}^{-1}$ for Bromus tectorum (Mack, 1989). These examples indicate that invasions are often faster than most natural migrations, for example following deglaciation (Clark, 1998).

The past decade has seen considerable advances in the study of dispersal. A hierarchy of processes operating at different temporal and spatial scales determines the dynamics of biological invasions. Longdistance dispersal events (LDD; dispersal beyond the local patch or cluster of conspecifics) may occur during periods of negligible population increase and appear to bear little relationship to population size. Invasive species rarely move across the landscape as a continuous front and both local and longdistance dispersal determine spatial patterns (Pyšek and Hulme, 2005). The recognition of the important role of long-distance dispersal has changed the way ecologists view species dynamics (Nathan, 2005). For instance, it now appears that traits typically associated 
with 'normal' dispersal capacity (eg, seed mass and morphology) are inappropriate for predicting the potential spread dynamics of a species. Infrequent, long-distance dispersal events, often via non-standard means of dispersal (Higgins et al., 2003) ultimately control the rate of spread (Higgins and Richardson, 1999). Increasingly, post introduction dispersal by human agency (intentional or accidental) is probably the most significant driver of many plant invasions (Hodkinson and Thompson, 1997). One implication of this is that modelling the spread of alien species assuming 'normal' dispersal is likely to produce marked underestimates of spread rates, certainly at scales beyond the landscape (Pyšek and Hulme, 2005; Rejmánek et al., 2005a). The underlying assumption that seed dispersal follows a diffusion process led to the formulation of 'Reid's paradox of rapid plant migration' since the rates of spread predicted by such models are much slower than those observed for the postglacial advance of trees (Clark et al., 1998). LDD is extremely difficult to measure so a large proportion of variation remains unexplained in such studies, although significant correlates are found. Alien plants often produce more propagules in their introduced ranges (eg, Hönig et al., 1992), which makes LDD more likely than in their native ranges, accounting, at least in part, for their invasive behaviour. This has profound implications for the capacity of alien species to spread across fragmented landscapes (Richardson et al., 2000b; With, 2004) and, ultimately, for their capacity to respond to changing environmental conditions. This is one reason why alien plant species are likely to become increasingly dominant as global change forces range shifts. LDD is potentially an important unifying theme for linking invasion ecology with other fields such as conservation biology, with the realization that limited LDD is a key factor for consideration in the management of rare species, whereas excessive LDD is the major driver of biological invasions (Trakhtenbrot et al., 2005).

\section{Traits do matter - a theory of seed plant invasiveness}

Many studies have attempted to profile successful invaders, starting with the work of Baker (1965) on identifying the traits of the 'ideal weed', an idea now considered simplistic (Perrins et al., 1993). Subsequent studies have identified characteristics associated with reproductive potential, vegetative reproduction and dispersal as important correlates of invasiveness (eg, Forcella et al., 1986; Noble, 1989; Roy, 1990; Richardson and Cowling, 1992; Thompson et al., 1995; Crawley et al., 1996). A limitation of such studies is, however, the lack of relevant information for most plant species. Good data are available for plant height, growth form, seed mass and (apparent) dispersal syndrome, but data on growth rates, palatability, seed production, and many other traits that are crucial for invasion success (Pyšek et al., 2004a; Rejmánek et al., 2005b) are, in many cases, lacking or of dubious quality. It has become obvious that finding a set of traits associated with invasiveness that applies to all vascular plants is an unrealistic aim (Williamson, 1999). Consequently, the focus has shifted to exploring the components of invasiveness at a finer taxonomic scale or for particular life forms. For example, Rejmánek and Richardson (1996) were able to explain invasiveness in Pinus species using only three traits (seed mass, length of juvenile period and interval between seed mast years). They defined a discriminant function that successfully separated invasive and non-invasive species. This framework was expanded, by adding considerations relating to dispersal by vertebrates and characteristics of fruits, and successfully applied to predict invasiveness in other gymnosperms and woody angiosperms (Rejmánek and Richardson, 1996; Richardson and Rejmánek, 2004).

Marcel Rejmánek's 'theory of seed plant invasiveness' is the most ambitious attempt to date to synthesize available knowledge into a unified scheme (Rejmánek, 1996; 2000; Rejmánek et al., 2005a; 2005b). It highlights a 
low nuclear amount of DNA as a result of selection for the short generation time, membership to alien genera (but see section VI), and primary latitudinal range as major factors contributing to the invasiveness of seed plants. Large geographical range is often among the best predictors of invasion success (Goodwin et al., 1999; Scott and Panetta, 1993; Rejmánek, 1995). Widespread species are more likely to be dispersed because they occur in more locations and have higher chances to be dispersed, and they are more likely to be adapted to wider range of conditions (Booth et al., 2003). Although there are exceptions to this rule reported for individual species (Richardson and Bond, 1991), it seems that the same traits that allow a species to be widespread in the native range are also favourable for a successful invasion (Booth et al., 2003). An additional study identified RGR as the most important predictor of invasiveness in disturbed habitats and related invasiveness to physiological measures (Grotkopp et al. , 2002).

When analysing large comparative data sets, potentially confounding effects of phylogenetic relatedness should be taken into account to distinguish between ecological and evolutionary explanations (Harvey and Pagel, 1991; Westoby et al., 1995). Only a few studies looking at traits associated with invasiveness have applied phylogenetic correction, either by employing phylogenetically independent contrasts (Crawley et al., 1996; Pyšek, 1997; Grotkopp et al., 2002; Kühn et al., 2004; Rejmánek et al. , 2005a), or by comparing each naturalized species with a closely related nonnaturalized (Goodwin et al., 1999). Using the former approach, Crawley et al. (1996) found invasiveness in British plants to be associated with tall stature, large seed size, pattern of dormancy, mode of pollination and time of flowering (see also Pyšek et al. , 2003c). Compared to native, alien plants seem to 'try harder', exhibiting more extreme features (being either very small or very big, flowering very early or very late, non-dormant or with long dormancy). This indicates that they may occupy vacant niches at both ends of the spectrum (Crawley et al., 1996).

\section{Owls are not what they seem - level of invasion, invasibility and propagule pressure}

Variations in the level/extent of invasion among recipient communities could be simply due to differences in the number of aliens arriving in the community (Williamson, 1996; Lonsdale, 1999; Hierro et al., 2005; Chytrý et al., 2005). To know whether a region, community or habitat is more invasible we need to ask not only whether it has more alien species, but whether it is intrinsically more susceptible to invasions (Lonsdale, 1999). Intrinsic invasibility can only be determined if processes of immigration and extinction are taken into account. Most invading species fail to establish (see section III), so the number of alien species in a region (community, habitat) is the product of the number of alien species introduced $\boldsymbol{S}$ and their survival rate $\boldsymbol{I}$ in the new environment. It is useful to break down both parameters further - the number of introduced species into accidental and intentional introductions, and survival rate into losses attributable to competition, herbivory, chance, pathogens, and maladaptations associated with release of a species into unsuitable environment (Lonsdale, 1999). Clearly, 'more invaded' does not necessarily mean 'more invasible' and real differences in invasibility can only be assessed by analysing residuals from the relationship between invasion success and propagule pressure (Williamson, 1996), which determines $S$ in Lonsdale's equation.

That propagule pressure, both in space (by widespread dissemination, abundant plantings) and/or time (by long history of cultivation) can fundamentally influence the probability of invasions by alien species has been convincingly demonstrated (Mulvaney, 2001; Kowarik, 1995; Crooks and Soulé, 1999; Richardson, 1999; Rejmánek, 2000; Kolar and Lodge, 2002; Williams et al. , 2002; Rouget and Richardson, 2003; Brown and 
Peet, 2003, Kühn et al., 2004; Foxcroft et al., 2004). This finding corroborates growing evidence that plant populations are seed limited (Turnbull et al., 2000; Parker, 2001; Seabloom et al., 2003). When studying invasibility at the scale of large areas (habitats, communities, regions), propagule pressure is extremely difficult to measure. Various quantitative surrogates for propagule pressure including the number of visitors to nature reserves (Lonsdale, 1999; McKinney, 2002), human population size or density (Pyšek et al., 2002a; 2003a; McKinney, 2001; 2002; Taylor and Irwin, 2004), the amount of trade and tourism (Thuiller et al., 2005) or economic activity (Taylor and Irwin, 2004) have been used with reasonable success.

Models incorporating propagule pressure are proving markedly superior to those invoking only environmental parameters for explaining distribution patterns and abundance of invaders at a regional scale. Attempts to model ongoing and predict future invasions must therefore incorporate propagule pressure (Rouget and Richardson, 2003). While adding more propagules to sites increases establishment success, the relative importance of propagule pressure compared with that of other factors such as disturbance and resource supply is not well understood (Hierro et al., 2005). Once propagule pressure of invaders is factored out, both physical and biotic factors determining the outcome of plant invasion can be studied (Chaneton et al., 2002), but controversy persists over which prevail (Tilman, 1997; Levine and D'Antonio, 1999; Naeem et al., 2000; see section VII). Carefully designed factorial field experiments in which a range of propagule pressures are crossed with different levels of the other influential factors could improve our understanding of invasion mechanisms (Hierro et al., 2005). Studies are also needed to determine the extent to which propagule pressure can compensate for low inherent species invasiveness (Richardson and Rejmánek, 2004) and/or low intrinsic community invasibility (D'Antonio et al.,
2001). The issue of propagule pressure is closely related to ecological resistance which is determined by both biotic (see section XI) and abiotic factors. A simple conceptual framework of how variation in propagule pressure interacts with abiotically determined ecological resistance was suggested by D'Antonio et al. (2001). When resistance is low, few propagules are needed for an invader to establish in a community and the rate of invasion is fast. High resistance can be overcome only if the rate of propagule supply is high or if invaders themselves alter the resistance of the community.

Lonsdale's concept of invasibility has proved extremely useful in emphasizing the role of propagule pressure and pointing out the difference between invasibility (or vulnerability to invasion) of a region, community or habitat and a simple number of invasive species it harbours; for the latter the term 'level of invasion' (Hierro et al., 2005; Chytrý et al., 2005) seems to be more appropriate. Yet many studies label sites with higher numbers of invasive species as being more invasible (eg, Planty-Tabacchi et al., 1996; Naiman and Decamps, 1997; Hood and Naiman, 2000). The concept also drew attention to determinants of alien species' survival in a new region, which can be tested experimentally, and stimulated analyses aimed at disentangling the effect of particular factors determining invasibility (Chown et al., 1998; McKinney, 2001; 2002; Pyšek et al., 2002a; 2005). To compare the invasibility of plant communities or vegetation types, factors potentially biasing differences in their intrinsic invasibility such as area, climate, and soil need to be controlled (Pyšek et al., 2002a).

Global-scale studies focused on habitatrelated correlates of invasibility and/or the level of invasion have made it possible to sketch the 'big picture' and to evaluate hypotheses generally accepted but rarely rigorously tested before (Lonsdale, 1999). Robust geographical patterns have emerged, confirming among other things that islands are more invasible than mainland (Darwin, 
1845, cited by Cassey, 2003; Rejmánek, 1996; Lonsdale, 1999; Denslow, 2003), temperate agricultural or urban sites are the most invasible biomes, and that the New World is more invasible than Old World (but only if a surrogate for habitat diversity is factored out; Lonsdale, 1999). Invasibility increases with latitude on mainland but not on islands (Lonsdale, 1999), and tropical areas are less invaded than extratropical regions (Rejmánek, 1996), but species naturalized in tropics have larger geographical ranges (Sax, 2001). The number of naturalized species is negatively correlated and geographical range size is positively correlated with latitude (Rapoport's rule; Sax, 2001). On mainlands, ranges of alien species rarely exceed the lower latitudinal limit of their native ranges, but on islands they do because of reduced biotic pressure (Sax, 2001). The inherent superiority, acquired through evolutionary time, of dominant mainland species from species-rich regions has been suggested as one factor contributing to the high invasibility of islands, and as an explanation for the apparent paradox that introduced species can displace native species that are, presumably, well adapted to their native environment (Sax and Brown, 2000). Similarly, global reviews of the performance of selected taxa in a wide range of localities, differing in the level of disturbance, shed new light on habitat invasibility (Richardson and Bond, 1991).

\section{Diversity and invasibility - the illusive link}

Principles of the biotic resistance hypothesis (also termed the 'diversity resistance hypothesis' or the 'species richness hypothesis') were raised by Elton (1958) who suggested a negative relationship between native species diversity and community invasibility. Numerous studies have indeed found speciesrich communities to be less invasible (eg, Rejmánek, 1989; Tilman, 1997; 1999; Knops et al., 1999; Levine, 2000; Naeem et al., 2000; Dukes, 2002; Kennedy et al., 2002), but others found areas with a high species diversity to harbour more alien species (Timmins and Williams, 1991; Lonsdale, 1999; Planty-Tabacchi et al., 1996; Stohlgren et al., 1999; Lonsdale, 1999; Stadler et al., 2000; Pyšek et al., 2002a; McKinney, 2001). Empirical tests of the effects of species richness on invasibility have produced unambiguous results (Levine and D'Antonio, 1999). Most of the evidence for biotic resistance, ie, the negative relationship, comes from experimental work using synthetic assemblages that vary in diversity, while large-scale observational studies have mostly shown a positive correlation between diversity and invasibility (Levine, 2000; Naeem et al., 2000; Levine et al., 2002; Hierro et al., 2005). This discrepancy is mostly due to the spatial scale of observation (Fridley et al., 2004; Herben et al., 2004) and can be explained by covarying external factors (Shea and Chesson, 2002). At the large scale, the same abiotic conditions that promote high diversity of native species (climate, substrate, habitat heterogeneity, etc) also support diverse alien floras; in other words, what is good for natives is good for aliens too.

Elton's hypothesis rests on the theoretical notion that, in less diverse communities, intraspecific interactions are weaker because more empty niches are available (MacArthur, 1972; Crawley, 1987). Reduced resource uptake in species-poor communities (Tilman et al., 1996; Hooper and Vitousek, 1998), leading to more free resources, renders species-poor communities more invasible than species-rich communities (Hierro et al., 2005). Where competition-driven extinction dominates, leading to resource complementarity or space limitation (particularly likely at small scales owing to direct interactions between species; Huston, 1999) we should expect a negative correlation between diversity and invasibility (Brown and Peet, 2003). However, competitive interactions alone are unlikely to explain the observed patterns; there appear to be only few 'super-invaders' that have universal superior performance over co-occurring native species. Based on 79 case 
studies of competition between native and invasive species, Daehler (2003) found that alien invaders were not statistically more likely to be competitively superior, but rather that the relative performance of invaders and co-occurring natives was context-dependent. Moreover, in 55 situations when data on pairs of aliens and native exposed to various growing conditions (resource availability, disturbance regimes) are available, the performance of natives was superior to that of aliens at least for some key performance in some of the growing condition (Daehler, 2003). Models of competition predict and field experiments have confirmed that higher diversity leads to higher primary productivity; the relationship results both from the sampling effect and niche differentiation effect and leads to more complete utilization of limiting resources at higher diversity (Tilman, 1999). The low invasibility of high diversity communities thus results from the uniformly low levels of resources that occur in these communities (Tilman, 1999; 2004; Fargione et al., 2003).

Species-rich communities occur in habitats with high levels of heterogeneity in terms of climate, soil and topography. Alien species are more likely to find suitable habitats to invade in more heterogeneous habitats than in less heterogeneous habitats (Huston and De Angelis, 1994). If factors amenable to high species diversity also lower invasion resistance, the positive relationship between both variables observed on broad spatial scales is explained. At finer scales, for fixed extrinsic conditions, a negative pattern of invasibility as a function of species diversity is predicted. The broad-scale positive relationship is then the outcome of combining data from a series of negative relationships where each negative relationship comes from different extrinsic conditions (Shea and Chesson, 2002). The positive correlation between alien and native plant diversity found in most large-scale studies therefore occurs because native plant diversity is a proxy variable for habitat diversity (Lonsdale, 1999; Pyšek et al., 2002a; McKinney, 2002).
Most studies exploring the effects of species diversity on invasibility focus simply on the number of species but community composition and species identity have been shown to be important for the interpretation of observed effects, which may not be due to richness itself but to the overriding effect of keystone species (Booth et al., 2003). Crawley et al. (1999) found species identity to be more important in determining both the number of invading species and the total biomass of invasives than species richness per se. Assemblages with more species are more likely to have some members able to thwart invading species (Grime, 1997; Hooper and Vitousek, 1998; Lepš et al., 2001). Furthermore, simulation models suggest that processes regulating species richness in resident communities crucially affect the pattern of invasibility along species richness gradients (Moore et al., 2001) and that the diversityinvasibility relationship depends on the size of the species pool (Herben et al., 2004; Herben, 2005). This suggests that the focus of research in this area should shift from considering species richness as a synthetic variable to an approach that recognizes the importance of species identities and mechanisms of coexistence.

Species richness may be simply too broad a factor to explain observed differences in community invasibility (Levine and D'Antonio, 1999). Other factors such as disturbance, nutrient availability, climate and propagule pressure can covary with species richness; by exerting different effects on invasive and resident species (Siemann and Rogers, 2003; Leishman and Thomson, 2005), they can affect the relationship between species richness and invasibility in numerous ways (Levine and D'Antonio 1999; Levine, 2000; Naeem et al., 2000; Shea and Chesson, 2002). Generally, in disturbed environments, abiotic factors seem to be more pivotal as determinants of invasibility than biotic factors (Richardson and Bond, 1991; Hood and Naiman, 2000). Recent studies have also found little general support for the role of 
biotic resistance in determining geographical patterns of establishment of introduced species but have found evidence for a dominant effect of climate matching (Lodge, 1993; Chown et al., 1998; Gaston et al., 2003; Thuiller et al., 2005). One factor known to facilitate invasibility at larger spatial scales is resource availability (Hobbs and Huenneke, 1992; Davis et al., 2000; Davis and Pelsor, 2001); this sometimes explains more variance in invasibility than species richness (Foster et al., 2002). Given that resource supply and diversity of natives, when considered separately, appear to have opposite effects on invasion resistance, the critical issue is how these factors interact to mediate community invasibility (Hierro et al., 2005). To better understand the relationship between species richness and invasibility, species richness must be manipulated in situ in order to separate its effects from covarying factors (Foster et al., 2002; Von Holle, 2005). However, obtaining a more general picture is complicated by the fact that it is difficult to extend the results of biodiversity-manipulation experiments to argue that diverse communities in nature are inherently less invasive than species-poor ones (Naeem et al., 2000). Also, as pointed out by Hierro et al. (2005), correlative largescale observational studies have not controlled for extrinsic factors known to covary with diversity and that also may influence invasibility, such as propagule pressure, disturbance, resource availability and consumers (Levine and D'Antonio, 1999; Shea and Chesson, 2002). Experimental studies, on the other hand, have controlled for these factors essentially by ignoring them. This limits our understanding of how diversity interacts with processes that vary over broader spatial scales (Hierro et al., 2005).

\section{Catch if catch can - fluctuating resources, fluctuating invasibility}

Besides the insights on invasibility from correlative studies (reviewed above), numerous recent studies have explored the determinants of invasibility (the capacity or susceptibility of a community to accept new members) from a more mechanistic perspective. Most results from such studies are context-specific with little potential for generalization. Among the various attempts at unifying the many factors potentially influencing invasibility we find four particularly useful: Alpert et al. (2000), Davis et al. (2000), D'Antonio et al. (2001) and Huston (2004). All of them integrate, to various levels and in different ways, the roles of disturbance, competitive release, resource availability, and propagule pressure. The most widely embraced of these has been the 'fluctuating resources theory of invasibility' (Davis et al., 2000) which posits that invading species must have access to available resources, eg, light, nutrients, and water, and that an invading species will be more successful at invading a community if it does not encounter intense competition for these resources from resident species. By using insights from experiments and long-term monitoring studies, the theory identifies fluctuation in resource availability as the key factor controlling invasibility (Davis et al., 2000). There is good evidence that intermittent resource enrichment or release (often due to disturbance) increases community susceptibility to invasions, and that invasions occur if this coincides with availability and arrival of suitable propagules. Many studies attest to invasion being facilitated by increasing water or nitrogen availability (eg, Seabloom et al., 2003). Experimental evidence has confirmed that the larger the difference between gross resource supply and resource uptake, the more susceptible the community to invasion, and that a short fluctuation in resource availability had a long-term impact on the outcome of an invasion (Davis and Pelsor, 2001).

\section{Bitches' brew - synergisms, mutualisms, ecosystem engineers and invasional meltdown}

Until recently, research on the interactions between invasive species and other resident species in the invaded range dealt largely with 
the harmful effects of the invaders. This trend, of greater emphasis on negative than on positive or facilitating interactions, has been evident throughout ecology (see discussion in Richardson et al., 2000a). In the past decade or so, more attention has been given to positive interactions in ecology (Bruno et al., 2003) and work on invasive species has been enlightening in this regard. In many cases, the success of an alien species (ie, its ability to overcome various barriers in the new environment) depends on the presence of other species (native or alien) already resident in the area (Richardson et al., 2000a). Such interactions may counter, and potentially override, any inherent biotic resistance - a fact that is generally overlooked in discussions of biotic resistance (eg, Levine et al., 2004). The presence of alien species is making some areas more susceptible to invasion by other alien species (Richardson et al., 2000a). Sometime this process may produce entirely novel ecosystems dominated by a suite of species other than those native to the site (Hobbs et al., 2006). Simberloff and Von Holle (1999) introduced the term 'invasional meltdown' to describe such synergistic interactions among invaders that accelerate invasions and amplify their effects on native communities. The term, now widely applied in the invasion literature ( $>120$ citations in five years), is, however, often used with reference to any escalation in the net effects of invasive organisms at a site, rather than true synergistic effects. Dramatic evidence has emerged recently regarding the potentially facilitative effects of soil biota for invading plants. Positive interactions with soil biota have been shown to facilitate invasions for some plant species (Richardson et al., 2000a; Klironomos, 2002; Reinhart et al., 2003; Callaway et al., 2004). Some studies have identified switches from negative plant-soil community feedback in native ranges to positive plant-soil community feedback in the adventive ranges (Callaway et al., 2004). Such positive feedbacks point to 'invasional meltdown'.
The concept of invasional meltdown is also closely linked to that of 'ecosystem engineers' - organisms that affect resource availability, directly or indirectly, by altering abiotic or biotic features of an ecosystem (Jones et al., 1994). Many invasive plant species qualify as ecosystem engineers (Crooks, 2002), though not all invaders alter habitats in such a way as to facilitate further invasions. Where alien plant ecosystem engineers most clearly drive invasional meltdown is where the initial invasion totally alters ecosystem processes such as the fire regime. Probably the best example of this is the 'grass-fire cycle' in which invasive alien grasses change the distribution and abundance of fine fuels, resulting in more frequent fires (and in some cases introducing regular fires to non fire-prone ecosystems). This profound alteration of ecosystem functioning, which often favours further invasion of fire-tolerant alien species, has had radical effects on biodiversity in many semi-arid systems (D'Antonio and Vitousek, 1992). Similar effects are evident for plants other than grasses. For example, invasion of South African fynbos by serotinous trees and shrubs disrupts the prevailing non-equilibrium condition of cyclical replacement of native shrubs, instituting a depauperate steady-state system which favours a suite of aliens including Hakea and Pinus species (Richardson and Cowling, 1992).

\section{Conclusions}

Exciting progress has been made in all of the facets of plant invasion ecology reviewed in this paper. Advances are partly attributable to the fact that good research has been done at multiple levels and scales and that the conceptualization of processes mediating invasions has helped to focus efforts on elucidating factors responsible for key phase-transitions. The lack of standardized categorization of alien plants in different parts of the world is a problem. The adoption of a global standard would facilitate improved generalizations concerning levels of invasiveness and invasibility. The large number of good case studies undertaken 
recently has improved our ability to make robust generalizations and move towards mechanistic and predictive models. Models are starting to embrace both species invasiveness and community invasibility, providing a measure of integration. The stage is set for further advances. Molecular ecology has huge scope for shedding light on crucial gaps in our knowledge. For example, since seed dispersal, and especially rare long-distance dispersal events, is difficult to measure in the field, insights from molecular studies are needed to unravel key unknowns in invasion dynamics. Many of the concepts reviewed here are amenable to testing in manipulative experiments; increased robustness of generalizations and theories can be expected through experimentation. Improved integration of perspectives from all fields of research is needed to improve our ability to manage invasions.

\section{Acknowledgements}

We thank many colleagues, too many to name here, who have discussed their work with us over the years, and who acted as sounding boards for various ideas expressed in this paper. Thanks to Şerban Procheş and John Wilson for useful comments on a draft of the paper. DMR acknowledges support from the DST-NRF Centre of Excellence for Invasion Biology. PP was supported by the European Union within the FP 6 Integrated Project ALARM (GOCE-CT-2003-506675) and by institutional long-term research plans no. AV0Z60050516 from the Academy of Sciences of the Czech Republic, and no. 0021620828 from MSMT CR.

\section{References}

Abbott, R.J. 1992: Plant invasions, interspecific hybridization and the evolution of new plant taxa. Trends in Ecology and Evolution 7, 401-405.

Abbot, R.J. and Lowe, A. 2004: Origins, establishment and evolution of new polyploid species: Senecio cambrensis and S. eboracensis in the British Isles. Biological Journal of the Linnean Society 82, 467-74.

Alpert, P., Bone, E. and Holzapfel, C. 2000: Invasiveness, invasibility and the role of environmental stress in the spread of non-native plants. Perspectives in Plant Ecology, Evolution and Systematics 3, 52-66.
Amsellem, L., Chevallier, M.H. and Hossaert-McKey, M. 2001: Ploidy level of the invasive weed Rubus alceifolius (Rosaceae) in its native range and in areas of introduction. Plant Systematics and Evolution 228, 171-79.

Baker, H.G. 1965: Characteristics and modes of origin of weeds. In Baker, H.G. and Stebbins, G.L., editors, The genetics of colonizing species, New York: Academic Press, 147-72.

Batianoff, G.N. and Franks, A.J. 1997: Invasion of sandy beachfronts by ornamental plant species in Queensland. Plant Protection Quarterly 12, 180-86.

Binggeli, P. 1996: A taxonomic, biogeographical and ecological overview of invasive woody plants. Journal of Vegetation Science 7, 121-24.

Blossey, B. and Nötzold, R. 1995: Evolution of increased competitive ability in invasive nonindigenous plants: a hypothesis. Journal of Ecology 83, 887-89.

Booth, B.D., Murphy, S.D. and Swanton, C.J. 2003: Weed ecology in natural and agricultural systems. Wallingford: CABI Publishing.

Bossdorf, O., Auge, H., Lafuma, L., Rogers, W.E., Siemann, E. and Prati, D. 2005: Phenotypic and genetic differentiation between native and introduced plant populations. Oecologia 144, 1-11.

Bossdorf, O., Prati, D., Auge, H. and Schmid, B. 2004: Reduced competitive ability in an invasive plant. Ecology Letters 7, 346-53.

Brown, R.L. and Peet, R.K. 2003: Diversity and invasibility of southern Appalachian plant communities. Ecology 84, 32-39.

Bruno, J.F., Stachowicz, J.J. and Bertness, M.D. 2003: Inclusion of facilitation into ecological theory. Trends in Ecology and Evolution 18, 119-25.

Byers, D.L. and Quinn, J.A. 1998: Demographic variation in Alliaria petiolata (Brassicaceae) in four contrasting habitats. Journal of the Torrey Botanical Society 125, 138-49.

Callaway, R.M., Thelen, G.C., Rodriguez, A. and Holben, W.E. 2004: Soil biota and exotic plant invasion. Nature 427, 731-33.

Cassey, P. 2003: A comparative analysis of the relative success of introduced land birds on islands. Evolutionary Ecology Research 5, 1011-21.

Chaneton, E.J., Perelman, S.B., Omacini, M. and León, R.J.C. 2002: Grazing, environmental heterogeneity, and alien plant invasions in temperate Pampa grasslands. Biological Invasions 4, 7-24.

Chown, S.L., Gremmen, N.J.M. and Gaston, K.J. 1998: Ecological biogeography of southern ocean islands: species-area relationships, human impacts, and conservation. American Naturalist 152, 562-75.

Chytrý, M., Pyšek, P., Tichý, L., Knollová, I. and Danihelka, J. 2005: Invasions by alien plants in the Czech Republic: a quantitative assessment across habitats. Preslia 77, 339-54. 
Clark, J.S. 1998: Why trees migrate so fast: confronting theory with dispersal biology and the paleorecord. American Naturalist 152, 204-24.

Clark, J.S., Fastie, C., Hurtt, G., Jackson, S.T., Johnson, C., King, G.A., Lewis, M., Lynch, J., Pacala, S., Prentice, C., Schupp, E.W., Webb, T. and Wyckoff, P. 1998: Reid's paradox of rapid plant migration: dispersal theory and interpretation of paleoecological records. BioScience 48, 13-24.

Clements, D.R., DiTommaso, A., Jordan, N., Booth, B.D., Cardina, J., Doohan D., Mohler, C.L., Murphy, S.D. and Swanton, C.J. 2004: Adaptability of plants invading North American cropland. Agriculture, Ecosystems and Environment 104, 379-98.

Collier, M.H., Vankat, J.L. and Hughes, M.R. 2002: Diminished plant richness and abundance below Lonicera maackii, an invasive shrub. American Midland Naturalist 147, 60-71.

Crawley, M.J. 1987: What makes a community invasible? In Gray, A.J.C., Crawley, M.J. and Edwards, P.J., editors, Colonization, succession and stability, Oxford: Blackwell, 429-53.

Crawley, M.J., Brown, S.L., Heard, M.S. and Edwards, G.R. 1999: Invasion-resistance in experimental grassland communities: species richness or species identity. Ecology Letters 2, 140-48.

Crawley, M.J., Harvey, P.H. and Purvis, A. 1996: Comparative ecology of the native and alien floras of the British Isles. Philosophical Transactions of the Royal Society of London B 351, 1251-59.

Crooks, J. 2002: Characterizing ecosystem-level consequences of biological invasions: the role of ecosystem engineers. Oikos 97, 153-66.

Crooks, J. and Soulé, M. 1999: Lag times in population explosions of invasive species: causes and implications. In Sanderlund, O., Schei, P. and Viken, A., editors, Invasive species and biodiversity management, Dordrecht: Kluwer, 103-25.

Daehler, C.C. 1998: The taxonomic distribution of invasive angiosperm plants: ecological insights and comparison to agricultural weeds. Biological Conservation 84, 167-80.

- 2001: Darwin's naturalization hypothesis revisited. American Naturalist 158, 324-30.

- 2003: Performance's comparisons of co-occurring native and alien invasive plants: implications for conservation and restoration. Annual Review of Ecology and Systematics 34, 183-211.

Daehler, C.C. and Carino, D. 2001: Hybridization between native and alien plants and its consequences. In Lockwood, J.L. and McKinney, M., editors, Biotic homogenization, New York: Kluwer Academic/Plenum Publishers, 81-102.

D'Antonio, C.M. and Vitousek, P.M. 1992: Biological invasions by exotic grasses, the grass fire cycle, and global change. Annual Review of Ecology and Systematics 23, 63-87.
D'Antonio, C.M., Levine, J. and Thomsen, M. 2001: Propagule supply and resistance to invasion: a California botanical perspective. Journal of Mediterranean Ecology 2, 233-45.

Darwin, C. 1859: On the origin of species. London: Murray.

Davis, M.A. and Pelsor, M. 2001: Experimental support for a resource-based mechanistic model of invasibility. Ecology Letters 4, 421-28.

Davis, M.A., Grime, J.P. and Thompson, K. 2000: Fluctuating resources in plant communities: a general theory of invasibility. Journal of Ecology 88, 528-34.

De Candolle, A.P. 1855: Géographie botanique raisonné, volume 2, V. Paris: Masson.

Denslow, J.S. 2003: Weeds in paradise: thoughts on the invasibility of tropical islands. Annals of the Missouri Botanical Garden 90, 119-27.

DeWalt, S.J. and Hamrick, J.L. 2004: Genetic variation of introduced Hawaiian and native Costa Rican populations of an invasive tropical shrub, Clidemia hirta (Melastomataceae). American Journal of Botany 91, 1155-62.

Dietz, H., Steinlein, T. and Ullmann, I. 1999: Establishment of the invasive perennial herb Bunias orientalis L.: an experimental approach. Acta Oecologica 20, 621-32.

Drake, J.A., Mooney, H.A., Di Castri, F, Groves, R.H., Kruger, F.J., Rejmánek, M. and Williamson, M. 1989: Biological invasions: a global perspective. Chichester: Wiley.

Dukes, J.S. 2002: Species composition and diversity affect grassland susceptibility and response to invasion. Ecological Applications 12, 602-17.

Duncan, R.P. and Williams, P.A. 2002: Darwin's naturalization hypothesis challenged. Nature 417, 608.

Ellstrand, N.C. and Schierenbeck, K.A. 2000: Hybridization as a stimulus for the evolution of invasiveness in plants? Proceedings of the National Academy of Sciences of the United States of America 97, 7043-50.

Elton, C.S. 1958: The ecology of invasions by animals and plants. Chicago: University of Chicago Press.

Fargione, J., Brown. C.S. and Tilman, D. 2003: Community assembly and invasion: an experimental test of neutral versus niche processes. Proceedings of the National Academy of Sciences of the United States of America 100, 8916-20.

Forcella, F., Wood, J.T. and Dillon, S.P. 1986: Characteristics distinguishing invasive weeds within Echium (Bugloss). Weed Research 26, 351-64.

Foster B.L., Smith, V.H., Dickson, T.L. and Hildebrand, T. 2002: Invasibility and compositional stability in a grassland community: relationships to diversity and extrinsic factors. Oikos 99, 300-307.

Foxcroft, L.C., Rouget, M., Richardson, D.M. and MacFadyen, S. 2004: Reconstructing 50 years of Opuntia stricta invasion in the Kruger National Park, South Africa: environmental determinants and 
propagule pressure. Diversity and Distributions 10 , 427-37.

Fridley, J.D., Brown, R.L. and Bruno, J.F. 2004: Null models of exotic invasion and scale-dependent patterns of native and exotic species richness. Ecology 85, 3215-22.

Gaston, K.J., Jones, A.G., Hanel, C. and Chown, S.L. 2003: Rates of species introduction to a remote oceanic island. Proceedings of the Royal Society of London B 270, 1091-98.

Goodwin, B.J., McAllister, A.J. and Fahrig, J. 1999: Predicting invasiveness of plant species based on biological information. Conservation Biology 13, 422-26.

Grime, J.P. 1997: Biodiversity and ecosystem function: the debate deepens. Science 277, 1260-61.

Grotkopp, E., Rejmánek, M. and Rost, T.L. 2002: Toward a causal explanation of plant invasiveness: seedling growth and life-history strategies of 29 pine (Pinus) species. American Naturalist 159, 396-419.

Groves, R.H.C., Hosking, J.R., Batianoff, G.N., Cooke, D.A., Cowie, I.D., Johnson, R.W., Keighery, G.J., Lepschi, B.J., Mitchell, A.A., Moerkerk, M., Randall, R.P., Rozefelds, A.C., Walsh, N.G. and Waterhouse, B.M. 2003: Weed categories for natural and agricultural ecosystem management. Canberra: Bureau of Rural Sciences.

Harvey, P.H. and Pagel, M.D. 1991: The comparative method in evolutionary biology. Oxford: Oxford University Press.

Herben, T. 2005: Species pool size and invasibility of island communities: a null model of sampling effects. Ecology Letters 8, 909-17.

Herben, T., Mandák, B., Bímová, K. and Münzbergová, Z. 2004: Invasibility and species richness of a community: a neutral model and a survey of published data. Ecology 85, 3223-33.

Hierro, J.L., Maron, J.L. and Callaway, R.M. 2005: A biogeographical approach to plant invasions: the importance of studying exotics in their introduced and native range. Journal of Ecology 93, 5-15.

Higgins, S.I., Nathan, R. and Cain, M.L. 2003: Are long-distance dispersal events in plants usually caused by nonstandard means of dispersal? Ecology 84, 1945-56.

Higgins, S.I. and Richardson, D.M. 1999: Predicting plant migration rates in a changing world: the role of long-distance dispersal. American Naturalist 153, 464-75.

Hobbs, R. and Huenneke, L. 1992: Disturbance, diversity, and invasion: implications for conservation. Conservation Biology 6, 324-37.

Hobbs, R.J., Arico, S., Aronson, J., Baron, J.S., Bridgewater, P., Cramer, V.A., Epstein, P.R., Ewel, J.J., Klink, C.A., Lugo, A.E., Norton, D., Ojima, D., Richardson, D.M., Sanderson, E.W., Valladares, F, Vilà, M., Zamora, R. and Zobel, M. 2006: Novel ecosystems: theoretical and management aspects of the new ecological world order. Global Ecology and Biogeography 15, 1-7.
Hodkinson, D.J. and Thompson, K. 1997: Plant dispersal: the role of man. Journal of Applied Ecology 34, 1484-96.

Hönig, M.A., Cowling, R.M. and Richardson, D.M. 1992: The invasive potential of Australian banksias in South African fynbos: a comparison of the reproductive potential of Banksia ericifolia and Leucadendron laureolum. Australian Journal of Ecology 17, 305-14.

Hood, W.G. and Naiman, R.J. 2000: Vulnerability of riparian zones to invasion by exotic vascular plants. Plant Ecology 148, 105-14.

Hooper, D.U. and Vitousek, P.M. 1998: Effects of plant composition and diversity on nutrient cycling. Ecological Monographs 68, 121-49.

Hulme, P.E. 2003: Biological invasions: winning the science battles but losing the conservation war? Oryx 37, 178-93.

Hurka, H., Bleeker, W. and Neuffer, B. 2003: Evolutionary processes associated with biological invasions in the Brassicaceae. Biological Invasions 5, 281-92.

Huston, M.A. 1999: Local processes and regional patterns, appropriate scales for understanding variation in the diversity of plants and animals. Oikos 86, 393-401.

- 2004: Management strategies for plant invasions: manipulating productivity, disturbance, and competition. Diversity and Distributions 10, 167-78.

Huston, M.A. and De Angelis, D.L. 1994: Competition and coexistence - the effects of resource transport and supply rates. American Naturalist 144, 954-77.

Jakobs, G., Weber, E. and Edwards, P.J. 2004. Introduced plants of the invasive Solidago gigantea (Asteraceae) are larger and grow denser than conspecifics in the native range. Diversity and Distributions 10, 11-19.

Jones, C.G., Lawton, J.H. and Shachak, M. 1994: Organisms as ecosystem engineers. Oikos 69, 373-86.

Kennedy, T.A., Naeem, S., Howe, K.M., Knops, J.M.H., Tilman, D. and Reich, P. 2002: Biodiversity as a barrier to ecological invasion. Nature 417, 636-38.

Klironomos, J. 2002: Feedback with soil biota contributes to plant rarity and invasiveness in communities. Nature 417, 67-70.

Knops, J.M.H., Tilman, D., Haddad, N.M., Naeem, S., Mitchell, C.E.J., Haarstad, M., Ritchie, E., Howe, K.M., Reich, P. B., Siemann, E. and Groth, J. 1999: Effects of plant species richness on invasion dynamics, disease outbreaks, insect abundances and diversity. Ecology Letters 2, 286-93.

Kolar, C.S. and Lodge. D.M. 2002: Ecological predictions and risk assessment for alien fishes in North America. Science 298, 1233-36.

Kollmann, J. and Banuelos, M.J. 2004: Latitudinal trends in growth and phenology of the invasive alien 
plant Impatiens glandulifera (Balsaminaceae). Diversity and Distributions 10, 377-85.

Kowarik, I. 1995: Time lags in biological invasions with regard to the success and failure of alien species. In Pyšek, P., Prach, K., Rejmánek, M. and Wade, M., editors, Plant invasions: general aspects and special problems, Amsterdam: SPB Academic Publishing, 15-38.

Kühn, I., Brandenburg, M. and Klotz, S. 2004: Why do alien plant species that reproduce in natural habitats occur more frequently? Diversity and Distributions 10, 417-25.

Lee, C.E. 2002: Evolutionary genetics of invasive species. Trends in Ecology and Evolution 17, 386-91.

Leger, E.A. and Rice, K.J. 2003: Invasive California poppies (Eschscholzia californica Cham.) grow larger than native individuals under reduced competition. Ecology Letters 6, 257-64.

Leishman, M.R. and Thomson, V.P. 2005: Experimental evidence for the effects of additional water, nutrients and physical disturbance on invasive plants in low fertility Hawkesbury Sandstone soils, Sydney, Australia. Journal of Ecology 93, 38-49.

Lepš, J., Brown, V.K., Diaz Lenz, T.A., Gormsen, D., Hedlund, K., Kailová, J., Korthals, G.W., Mortimer, S.R., Rodriguez-Barrueco, C., Roy, J., Santa Regina, I., van Dijk, C. and van der Putten, W.H. 2001: Separating the chance effect from other diversity effects in the functioning of plant communities. Oikos 92, 123-34.

Levin, D.A. 2002: The role of chromosomal change in plant evolution. Oxford: Oxford University Press.

Levine, J.M. 2000: Species diversity and biological invasions: relating local process to community pattern. Science 288, 852-54.

Levine, J.M. and D'Antonio, C.M. 1999: Elton revisited: a review of evidence linking diversity and invasibility. Oikos 87, 15-26.

Levine, J.M., Adler, P.B. and Yelenik, S.G. 2004: A meta-analysis of biotic resistance to exotic plant invasions. Ecology Letters 7, 975-89.

Levine, J.M., Kennedy, T. and Naeem, S. 2002: Neighborhood scale effects of species diversity on biological invasions and their relationship to community patterns. In Loreau, M., Naeem, S. and Inchausti, P., editors, Biodiversity and ecosystem functioning, Oxford: Oxford University Press, 114-24.

Lodge, D.M. 1993: Species invasions and deletions: community effects and responses to climate and habitat change. In Kareiva, P.M., Kingsolver, J.G. and Huey, R.B., editors, Biotic interactions and global change, Massachusetts: Sinauer, 367-87.

Lonsdale, W.M. 1999: Global patterns of plant invasions and the concept of invasibility. Ecology 80 , 1522-36.

MacArthur, R.H. 1972: Geographical ecology. New York: Harper and Row.
Mack, R.N. 1989: Temperate grasslands vulnerable to plant invasions: characteristics and consequences In Drake, J.A., Mooney, H.A., di Castri, F., Groves, R.H., Kruger, F.J., Rejmánek, M. and Williamson, M., editors, Biological invasions: a global perspective, Chichester: Wiley, 155-79.

- 1996: Biotic barriers to plant naturalization. In Moran, V.C. and Hoffman, J.H., editors, Proceedings of the Ninth International Symposium on Biological Control of Weeds, Stellenbosch, South Africa, Rondebosch: University of Cape Town, 19-26.

Mandák, B., Pyšek, P. and Bímová, K. 2004: History of the invasion and distribution of Reynoutria taxa in the Czech Republic: a hybrid spreading faster than its parents. Preslia 76, 15-64.

Maron, J.L., Vilà, M., Bommarco, R., Elmendorf, S. and Beardsley, P. 2004: Rapid evolution of an invasive plant. Ecological Monographs 74, 261-80.

McKinney, M.L. 2001: Effects of human population, area, and time on non-native plant and fish diversity in the United States. Biological Conservation 100, 243-52.

- 2002: Influence of settlement time, human population, park shape and age, visitation and roads on the number of alien plant species in protected areas in the USA. Diversity and Distributions 8, 311-18.

Mooney, H.A. 1999: A global strategy for dealing with alien invasive species. In Sanderlund, O., Schei, P. and Viken, A., editors, Invasive species and biodiversity management, Dordrecht: Kluwer, 407-18.

Moore, J.L., Mouquet, N., Lawton, J.H. and Loureau, M. 2001: Coexistence, saturation and invasion resistance in simulated plant assemblages. Oikos 94, 303-14.

Müllerová, J., Pyšek, P., Jarošík, V. and Pergl, J. 2005: Aerial photographs as a tool for assessing the regional dynamics of the invasive plant species Heracleum mantegazzianum. Journal of Applied Ecology 42, 1042-53.

Mulvaney, M. 2001: The effect of introduction pressure on the naturalization of ornamental woody plants on south-eastern Australia. In Groves, R.H., Panetta, F.D. and Virtue, J.G., editors, Weed risk assessment, Collingwood: CSIRO Publishing, 186-93.

Naeem, S., Knops, J.M.H., Tilman, D., Howe, K.M., Kennedy, T. and Gale, S. 2000: Plant diversity increases resistance to invasion in the absence of covarying extrinsic factors. Oikos 91, 97-108.

Naiman, R.J. and Decamps, H. 1997: The ecology of interfaces: riparian zones. Annual Review of Ecology and Systematics 28, 621-58.

Nathan, R. 2005: Long-distance dispersal research: building a network of yellow brick roads. Diversity and Distributions 11, 125-30.

Noble, I. 1989: Attributes of invaders and the invading process: terrestrial and vascular plants. In Drake, J.A., Mooney, H., di Castri, F., Groves, R., Kruger, F., Rejmánek, M. and Williamson, M., editors, Biological 
invasions. a global perspective, Chichester: Wiley, 301-14.

Parker, I.M. 2001: Safe site and seed limitation in Cytisus scoparius (Scotch broom): invasibility, disturbance, and the role of cryptogams in a glacial outwash prairie. Biological Invasions 3, 323-32.

Parker, I.M., Rodriguez, J. and Loik, M.E. 2003: An evolutionary approach to understanding the biology of invasions: local adaptation and general-purpose genotypes in the weed Verbascum thapsus. Conservation Biology 17, 59-72.

Pauchard, A. and Alaback, P.B. 2004: Influence of elevation, land use, and landscape context on patterns of alien plant invasions along roadsides in protected areas of south-central Chile. Conservation Biology 18, 238-48.

Perrins, J., Fitter, A. and Williamson, M. 1993. Population biology and rates of invasion of three introduced Impatiens species in the British Isles. Journal of Biogeography 20, 33-44.

Planty-Tabacchi, A., Tabacchi, E., Naiman, R.J., Deferrari, C. and Decamps, H. 1996: Invasibility of species-rich communities in riparian zones. Conservation Biology 10, 598-607.

Preston, C.D., Pearman, D.A. and Hall, A.R. 2004 : Archaeophytes in Britain. Botanical Journal of the Linnean Society 145, 257-94.

Pyšek, A., Pyšek, P., Jarošík, V., Hájek, M. and Wild, J. 2003a: Diversity of native and alien plant species on rubbish dumps: effects of dump age, environmental factors and toxicity. Diversity and Distributions 9, 177-89.

Pyšek, P. 1997: Clonality and plant invasions: can a trait make a difference? In de Kroon, H., and van Groenendael, J., editors, The ecology and evolution of clonal plants, Leiden: Backhuys Publishers, 405-27.

- 1998: Is there a taxonomic pattern to plant invasions? Oikos 82, 282-94.

Pyšek, P. and Hulme, P.E. 2005: Spatio-temporal dynamics of plant invasions: linking pattern to process. Ecoscience 12, 345-54.

Pyšek, P. and Jaršík, V. 2005: Residence time determines the distribution of alien plants. In Inderjit, S., editor, Invasive plants: ecological and agricultural aspects, Basel: Birkhäuser Verlag, 77-96.

Pyšek, P., Brock, J.H., Bímová, K., Mandák, B., Jarošík, V., Koukolíková, I., Pergl, J. and Štěpánek, J. 2003b: Vegetative regeneration in invasive Reynoutria (Polygonaceae) taxa: the determinant of invasibility at the genotype level. American Journal of Botany 90, 1487-95.

Pyšek, P., Davis, M.A., Daehler, C.C. and Thompson, K. 2004a: Plant invasions and vegetation succession: closing the gap. Bulletin of the Ecological Society of America 85, 105-109.

Pyšek, P., Jarošík, V., Chytrý, M., Kropáč, Z., Tichý, L. and Wild, J. 2005: Alien plants in temperate weed communities: prehistoric and recent invaders occupy different habitats. Ecology 86, 772-85.

Pyšek, P., Jarošík, V. and Kučera, T. 2002a: Patterns of invasion in temperate nature reserves. Biological Conservation 104, 13-24.

Pyšek, P., Richardson, D.M., Rejmánek, M., Webster, G. L., Williamson, M. and Kirschner, J. 2004b: Alien plants in checklists and floras: towards better communication between taxonomists and ecologists. Taxon 53, 131-43.

Pyšek, P., Richardson, D.M. and Williamson, M. 2004c: Predicting and explaining plant invasions through analysis of source area floras: some critical considerations. Diversity and Distributions 10, 179-87.

Pyšek, P., Sádlo, J. and Mandák, B. 2002b: Catalogue of alien plant of the Czech Republic. Preslia, Praha 74, 97-186.

Pyšek, P., Sádlo, J., Mandák, B. and Jarošík, V. 2003c: Czech alien flora and the historical pattern of its formation: what came first to Central Europe? Oecologia 135, 122-30.

Randall, R.P. 2002: A global compendium of weeds. Melbourne: R.G. and F.J. Richardson.

Rapoport, E.H. 1991: Tropical versus temperate weeds: a glance into the present and future. In Ramakrishnan, P.S., editor, Biological invasions in the tropics, Delhi: International Scientific Publications, 41-51.

Reinhart, K.O., Packer, A., Van der Putten, W.H. and Clay, K. 2003: Plant-soil biota interactions and spatial distribution of black cherry in its native and invasive ranges. Ecology Letters 6, 1046-50.

Rejmánek, M. 1989: Invasibility of plant communities. In Drake, J.A., Mooney, H., di Castri, F., Groves, R., Kruger, F., Rejmánek, M. and Williamson, M., editors, Biological invasions. A global perspective, Chichester: Wiley, 369-88.

- 1995: What makes a species invasible? In Pyšek, P., Prach, K., Rejmánek, M. and Wade, M., editors, Plant invasions: general aspects and special problems, Amsterdam: SPB Academic Publishing, 3-13.

- 1996: A theory of seed plant invasiveness: the first sketch. Biological Conservation 78, 171-81.

- 1999: Invasive plant species and invasible ecosystems. In Sanderlund, O., Schei, P. and Viken, A., editors, Invasive species and biodiversity management, Dordrecht: Kluwer, 79-102.

- 2000: Invasive plants: approaches and predictions. Austral Ecology 25, 497-506.

Rejmánek, M. and Richardson, D. 1996: What attributes make some plant species more invasive? Ecology $77,1655-61$.

Rejmánek, M., Richardson, D.M., Higgins, S.I., Pitcairn, M.J. and Grotkopp, E. 2005a: Ecology of invasive plants: state of the art. In Mooney, H.A., Mack, R.M., McNeely, J.A., Neville, L., Schei, P. and Waage, J., editors, Invasive alien species: searching for solutions, Washington, DC: Island Press, 104-61. 
Rejmánek, M., Richardson, D.M. and Pyšek, P. 2005b: Plant invasions and invasibility of plant communities. In van der Maarel, E., editor, Vegetation ecology, Oxford: Blackwell, 332-55.

Reznick, D.N. and Ghalambor, C.K. 2001: The population ecology of contemporary adaptations: what empirical studies reveal about the conditions that promote adaptive evolution. Genetica 112-13, 183-98.

Richardson, D.M. 1999: Commercial forestry and agroforestry as sources of invasive alien trees and shrubs. In Sanderlund, O., Schei, P. and Viken, A., editors. Invasive species and biodiversity management, Dordrecht: Kluwer, 237-57.

Richardson, D.M. and Bond, W.J. 1991: Determinants of plant-distribution - evidence from pine invasions. American Naturalist 137, 639-68.

Richardson, D.M. and Cowling, R.M. 1992: Why is mountain fynbos invasible and which species invade? In van Wilgen, B.W., Richardson, D.M., Kruger, F.J., and van Hensbergen H.J., editors, Fire in South African mountain fynbos, Berlin: Springer-Verlag, 161-81.

Richardson, D.M. and Higgins, S.I. 1998: Pines as invaders in the southern hemisphere. In Richardson, D.M., editor, Ecology and biogeography of Pinus, Cambridge: Cambridge University Press, 450-73.

Richardson, D.M. and Rejmánek, M. 2004: Conifers as invasive aliens: a global survey and predictive framework. Diversity and Distributions 10, 321-31.

Richardson, D.M., Allsopp, N., D'Antonio, C.M., Milton, S.J. and Rejmánek, M. 2000a: Plant invasions - the role of mutualisms. Biological Reviews 75, 65-93.

Richardson, D.M., Pyšek, P., Rejmánek, M., Barbour, M.G., Panetta, F.D. and West, C.J. 2000b: Naturalization and invasion of alien plants: concepts and definitions. Diversity and Distributions 6, 93-107.

Rogers, W.E. and Siemann, E. 2004: Invasive ecotypes tolerate herbivory more effectively than native ecotypes of the Chinese tallow tree Sapium sebiferum. Journal of Applied Ecology 41, 561-70.

Rouget, M. and Richardson, D.M. 2003: Inferring process from pattern in plant invasions: a semimechanistic model incorporating propagule pressure and environmental factors. American Naturalist 162, 713-24.

Roy, J. 1990: In search of the characteristics of plant invaders. In di Castri, F., Hansen, A.J. and DeBussche, M., editors, Biological invasions in Europe and the Mediterranean Basin, Dordrecht: SPB Academic Publishers, 335-52.

Sax, D.F. 2001: Latitudinal gradients and geographic ranges of exotic species: implications for biogeography. Journal of Biogeography 28, 139-50.

Sax, D.F. and Brown, J.H. 2000: The paradox of invasion. Global Ecology and Biogeography 9, 363-71.
Scott, J.K. and Panetta, F.D. 1993: Predicting the Australian weed status of southern African plants. Journal of Biogeography 20, 87-93.

Seabloom, E.W., Borer, E.T., Boucher, V.L., Burton, R.S., Cottingham, K.L., Goldwasser, L., Gram, W.K., Kendall, B.E. and Micheli, F. 2003: Competition, seed limitation, disturbance, and reestablishment of California native annual forbs. Ecological Applications 13, 575-92.

Shea, K. and Chesson, P. 2002: Community ecology theory as a framework for biological invasions. Trends in Ecology and Evolution 17, 170-76.

Siemann, E. and Rogers, W.E. 2003: Increased competitive ability of an invasive tree may be limited by an invasive beetle. Ecological Applications 13, 1503-507.

Simberloff, D. and Von Holle, B. 1999: Positive interaction of nonindigenous species: invasional meltdown? Biological Invasions 1, 21-32.

Soltis, D.E. and Soltis, P.S. 1993: Molecular data and the dynamic nature of polyploidy. Critical Reviews in Plant Sciences 12, 243-73.

Stadler, J., Trefflich, A. Klotz, S. and Brandl, R. 2000: Exotic plant species invade diversity hot spots: the alien flora of northwestern Kenya. Ecography 23, 169-76.

Stebbins, G.L. 1985: Polyploidy, hybridization and the invasion of new habitats. Annals of the Missouri Botanical Garden 72, 824-32.

Stohlgren, T.J., Binkley, D., Chong, G.W., Kalkhan, M.A., Schell, L.D., Bull, K.A., Otsuki, Y., Newman, G., Bashkin, M. and Son, Y. 1999: Exotic plant species invade hot spots of native plant diversity. Ecological Monographs 69, 25-46.

Taylor, B.W. and Irwin, R.E. 2004: Linking economic activities to the distribution of exotic plants. Proceedings of the National Academy of Sciences of the USA 101, 17725-30.

Thébaud, C. and Simberloff, D. 2001: Are plants really larger in their introduced ranges? American Naturalist 157, 231-36.

Thompson, J.N. 1998: Rapid evolution as an ecological process. Trends in Ecology and Evolution 13, 329-32.

Thompson, K., Hodgson, J.G. and Rich, T.C.G. 1995: Native and alien invasive plants: more of the same? Ecography 18, 390-402.

Thuiller, W., Richardson, D.M., Pyšek, P., Midgley, G.F., Hughes, G.O. and Rouget, M. 2005: Niche-based modelling as a tool for prediction global risk of plant invasions. Global Change Biology 11, 2234-50.

Tilman, D. 1997: Community invasibility, recruitment limitation, and grassland biodiversity. Ecology 78, 81-92.

- 1999: The ecological consequences of changes in biodiversity: a search for general principles. Ecology 80, 1455-74.

- 2004: Niche tradeoffs, neutrality, and community structure: a stochastic theory of resource competition, invasion, and community assembly. Proceedings 
of the National Academy of Sciences of the USA 101, 10854-61.

Tilman, D., Wedin, D. and Knops, J. 1996: Productivity and sustainability influenced by biodiversity in grassland ecosystems. Nature 379, 718-20.

Timmins, S.M. and Williams, P.A. 1991: Weed numbers in New Zealand's forest and scrub reserves. New Zealand Journal of Ecology 15, 153-62.

Trakhtenbrot, A., Nathan, R., Perry, G. and Richardson, D.M. 2005: The importance of longdistance dispersal in biodiversity conservation. Diversity and Distributions 11, 173-81.

Turnbull, L.A., Crawley, M.J. and Rees, M. 2000: Are plant populations seed-limited? A review of seed sowing experiments. Oikos 88, 225-38.

Vila, M., Weber, E. and D'Antonio, C. 2000: Conservation implications of invasion by plant hybridization. Biological Invasions, 2, 207-17.

Villasenor, J.L. and Espinosa-Garcia, F.J. 2004: The alien flowering plants of Mexico. Diversity and Distributions 10, 113-23.

Von Holle, B. 2005: Biotic resistance to invader establishment of a southern Appalachian plant community is determined by environmental conditions. Journal of Ecology 93, 16-26.

Weber, E.F. 1997: The alien flora of Europe: a taxonomic and biogeographic review. Journal of Vegetation Science 8, 565-72.

- 2003: Invasive plant species of the world. A reference guide to environmental weeds. Wallingford: CABI Publishing.

Weber, E. and D'Antonio, C.M. 1999: Phenotypic plasticity in hybridizing Carpobrotus spp. (Aizoaceae) from coastal California and its role in plant invasions. Canadian Journal of Botany 77, 1411-18.

Westoby, M., Leishman, M.R. and Lord, J.M. 1995: On misinterpreting the 'phylogenetic correction'. Journal of Ecology 83, 531-34.

Williams, C.B. 1951: Intra-generic competition as illustrated by Moreau's record of East African bird communities. Journal of Animal Ecology 20, 246-53.

Williams, D.G., Mack, R.N. and Black, R.A. 1995: Ecophysiology of introduced Pennisetum setaceum on Hawaii - the role of phenotypic plasticity. Ecology 76, 1569-80.
Williams, P.A., Wilton, A. and Spenceret, N. 2002: A proposed conservation weed risk assessment system for the New Zealand border. Science for Conservation 208. Wellington: Department of Conservation.

Williamson, M. 1993: Invaders, weeds and the risk from genetically manipulated organisms. Experientia 49, 219-24.

- 1996: Biological invasions. London: Chapman and Hall.

- 1999: Invasions. Ecography 22, 5-12.

- 2000: The ecology of invasions. In Preston, G., Brown, G. and van Wyk, E., editors, Best management practices for preventing and controlling invasive alien species, Cape Town: The Working for Water Programme, 56-65.

Williamson, M. and Brown, K.C. 1986: The analysis and modelling of British invasions. Philosophical Transactions of the Royal Society London B 314, 505-21.

Williamson, M. and Fitter, A. 1996: The varying success of invaders. Ecology 77, 1661-66.

Willis, A.J., Memmott, J. and Forrester, R.I. 2000: Is there evidence for the post-invasion evolution of increased size among invasive plant species? Ecology Letters 3, 275-83.

With, K.A. 2004: Assessing the risk of invasive spread in fragmented landscapes. Risk Analysis 24, 803-15.

Wolfe, L.M., Elzinga, J.A. and Biere, A. 2004: Increased susceptibility to enemies following introduction in the invasive plant Silene latifolia. Ecology Letters 7, 813-20.

Wu, S., Chaw, S. and Rejmánek, M. 2003: Naturalized Fabaceae (Leguminosae) in Taiwan: the first approximation. Botanical Bulletin of Academia Sinica 44, 59-66.

Wu, S.-H., Hsieh, C.-F., Chaw, S.-M. and Rejmánek, M. 2004: Plant invasions in Taiwan: insights from the flora of casual and naturalized alien species. Diversity and Distributions 10, 349-62.

Zangerl, A.R. and Berenbaum, M.R. 2005: Increase in toxicity of an invasive weed after reassociation with its coevolved herbivore. Proceedings of the National Academy of Sciences of the United States of America 102, 15529-32. 
Copyright of Progress in Physical Geography is the property of Arnold Publishers and its content may not be copied or emailed to multiple sites or posted to a listserv without the copyright holder's express written permission. However, users may print, download, or email articles for individual use. 